\title{
A New Model of Information Systems Efficiency based on Key Performance Indicator (KPI)
}

\author{
Ahmad AbdulQadir AlRababah \\ Faculty of Computing and Information Technology in Rabigh, \\ King Abdulaziz University, \\ Rabigh 21911, Kingdom of Saudi Arabia
}

\begin{abstract}
Any company concerning with information technology considers Automated performance management processes as a key component of its operations as it enables the company get a clear long -term assessment about the performance of employees as well as operating units of the company. One technique that the company could use to evaluate the present performance of both employees and operating units is the utilization of KPI -based management information system. The current study seeks to provide a new model of information system efficiency based on key performance indicator and the extent to which such approach helps the company evaluate the performance within the company. In addition to recognize the requirements and criteria needed to establish an effective system of performance measurement, the axioms that may influence the designing of the Model KPIs and the approaches that We need to be contracted with a fixed set of key performance indicators in order to facilitate hiring.
\end{abstract}

Keywords-Information Systems Management; System performance; Key performance Indicators; Data warehouse; Information Systems Integration

\section{INTRODUCTION}

For modern enterprise management - process complexity is an important constraint of calibration solutions that needed to be taken, based on a very short time, a large number of financial analyses and other information. Modern manager should not only know how to solve problems quickly, but also forecast them on proper time, and help enterprises find new opportunities and achieve good prospects for the new development [5].

Indicators or key performance indicators (KPIs) in business environment are mostly quantitative information. It illustrates structures and processes of a company. Recently, KPIs are considered very important for planning and controlling over supporting information, creating transparency and supporting decision makers of the management ${ }^{1}$.

The article deals with the development of information systems (IS), which allows anyone to solve complex problems effectively in the world of business. At the core of the control system, efficiency is considered as a formal method for evaluating the performance staff members and operating units within the company. Key performance indicators, - KPI can be seen as a supporter that estimates misleading business process (BP) performed by staff members and operating units.

Modern business environment where information has become the most important resource requires new approaches

King AbdulAziz University- Kingdom of Saudi Arabia to asses performances of organizations .comparing to traditional performance measurement system which evolved just financial and accounting indicators, KPI. KPI is considered as one of the newest approaches that are used to financial and non- financial to reveal how successful companies have accomplished long -term goals. To constitute an effective system of performance measurement, it is very crucial to define and standardize all processes within the organization [8].

Many companies have utilized inappropriate measures; therefore such measures should not be called performance indicators (KPIs). In fact, most of the organizations that are considered to have true control system use key performance indicators and why there are accountants, business leaders and consultants have experience and sufficient information about Key Performance Indicators.

\section{MATERIALS AND METHODS}

There are four kinds of key performance indicators:

- (KRIs), That can say it has achieved critical success factor of perspective or purposefully

- (RIs): Here we can say that you have done.

- $\quad$ (PIs), He can say it what should be done .

- KPIs, Who can say that it must be done to increase the high degree of performance

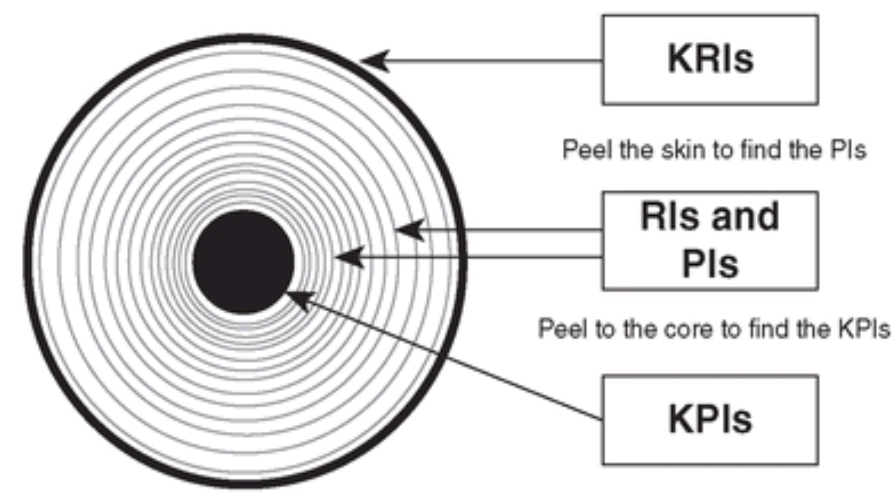

Fig. 1. Four kinds of key performance indicators

We will define key performance indicators by organizations, measures are being carried out by these organizations to review progress against goals and we will 
dividing these goals, which are to achieve progress by departments and individuals are reviewed these goals and achieve them and apply them at regular intervals by organizations [2].

- Input: Input consists of individuals and materials used to carry out the task and implement all the means to get the output

- Activities: are the methods used to input considered so as to generate outputs and outcomes at the end of the process

- Output: The output is the final product of goods and services produced

- Outcomes: Results are considered that affect the specific outcomes that should be the end of the strategic goals of the institutions and the results of performance that are supplied with plans

- Impacts: These exact results, which are carried out such as the creation of jobs for young people or reduce the need for organizations considered in order to prove how to use the available resources so as to obtain information on the precise results.

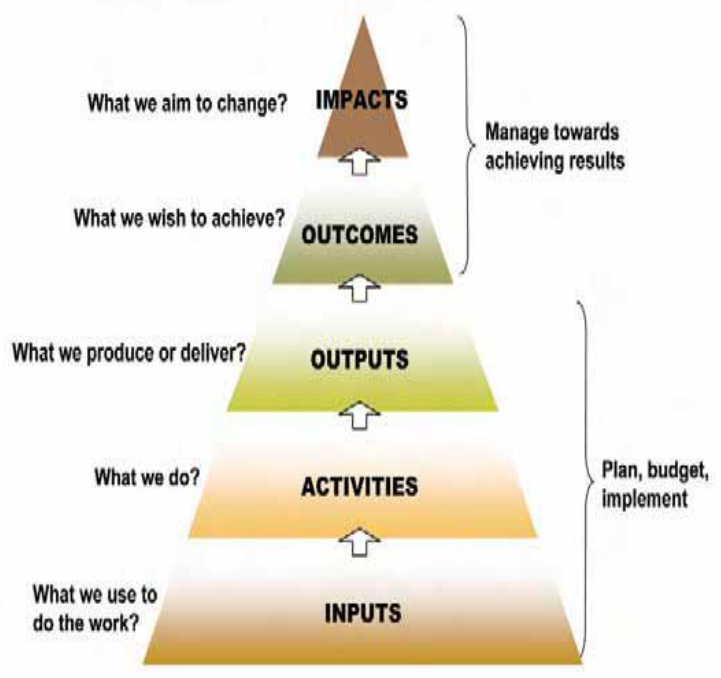

Fig. 2. Key performance information concepts

The researcher sees that a complete management information system should be in order to planning skills of the different variables and is considered a form Key Performance Indicators is a model designed for a short time but there is a goal of all this process, but elusive and the reason for this is to use a small number of Mini easy, simple and fast way, but in a comprehensive manner for the operational needs of managers, but are to achieve the interests the public is a form key performance indicators can be a cornerstone of the information management system $[4,8]$.

Here we will measure the design of the main performance on basic intuitions which are relevant to measure performance and to be developed without being influence the basic model indicators, performance has to be measured against goals fixed by the Courts;
First, must be linked to performance indicators targets performance and must be recorded important notes, but not all the courts that is reminiscent of the goals however that the courts will be affected generally be through the resolution of conflicts in accordance with the law through a fair, fast and efficient process and are key performance indicators in the form of focus on punctuality and be effective also in terms of cost, or what is known as case management or goal of the court system This is not to focus on the objectives or results of the process are not important to the contrary, as he can use the terminology to reduce the concentration and confirms that the performance respect to objectives through derived from the court system and plans procedural structural characteristics and see all the people in a bid to reduce the time and cost required to achieve targets a modest sense to try to do the same thing with the objectives of a fair process .

Second, it should be setting goals that in the measurement of the courts must rely on performance standards with respect to the general objectives in terms of cost and in terms of time and this has many rollover courts and performance standards to overcome the frustration and feelings of control used in therapy with less than measurement standards performance and this example to take advantage of the time and this is a completely failed to take into account that the process should be time-consuming to defend the distinctive Qaeda between the time that it takes for this process and that the delay is not justified and must be similar observations in terms of cost and that some effective

Third, it must be performance results follow more measures as the main performance of the courts are in accordance with the operation and the achievement of performance targets and is expected to indicators of performance are the work of the present and future of the court and must be of a physical link or are in accordance with the progress standards and should not call for them and must The issues to be a new beginning will generic terms that are required ideally to create a corrective action show

Finally, must be the main targets a few simple indicators in order to show the central idea, however, it should be doubled simply must Court, which maintained a session of the drought flood statistics show that after years of safety most data archaeological courts and are now producing full books on the tables and charts so as to improve the stomach reporting good numbers and considers this a tie with a significant space in the management of the operations day after day, however, it should be the objectives of the main work will be very easy to provide the maximum size of useful data with a minimum of information are in the form of loss easily must be The final message is simple $[3,5]$.

In March 1999, has been put forward a discussion paper to provide projects of key performance indicators in an attempt to control the judiciary and how the president administration for each of the courts of New South Wales were accepted several comments have been model correct in the light of this report, it has fought hard for each the false comments and how we can avoid that general and private performance indicators: The key performance indicators to measure the performance, which 
connects all the users of the service or are measured service aspects that are relevant to the user:

- General key performance indicators measured aspects of performance that are linked to the users of the service is not aimed at a specific class by itself.

- Private Key Performance Indicators is aimed at the user who performed a specific service designated bodies of nationals relevant to those users of the service.

The evolution of key performance indicators: These factors will be displayed as a series of stages may apply some of them and others do not occur at any step in this process is to identify these factors through the collection and analysis after a comprehensive review and must be set up key performance indicators

1) Introduce the public and use for measurement: To be necessary to determine the measurement objectives in order to identify and develop indicators appropriate performance and will observe whether the goal of the measurement is the comparison, both internally and in order to improve the quality or other institutions, which aims to influence the process of selection of key performance indicators if it is to prepare performance indicators to measure performance should be selected key performance indicators widely internationally and there are many high-quality areas such as efficiency security before the start of performance measurement process because it is important to identify the domain that you are measuring the performance to him and which are in turn dependent on the public for the quality of the product evaluated in order to determine balance between key performance indicators

2) Investigation a balance in measurement: Large numbers of the diversity of stakeholders in the field of health and sponsorships are needed to several areas to meet the information needs and the implementation of a number of ways to assist in the identification of a set of key performance indicators,

In the beginning of the panel, which was known by Kaplan and Norton, a dashboard and balanced, which proposes four views indicators specific goals to provide an opinion on the system

- Services expected of a member of that can measure the needs of the beneficiary and wait service

- The method of administration, which measure the basic mode of action that are identified as significant and effective task

- It is measuring an idea to improve communication systems and the ability of the public

The evaluation of the efficient use of resources to achieve the objectives of the arrangement and used in the economy and efficiency

3) Indicator definition: That kind are provided, such as this form of collapse that must be included when applying key performance indicators and model access to the key elements that must be taken when determining indicators main performance, however template is typically to retrieve the requirements that improve indicators main performance in separate services

4) Consult with stakeholders and advisory group: This type there must be consultation with all stakeholders along the preparation of the data and the process of consultation with each other to help identify their needs at the same time to accept the main performance indicators also facilitates consultation on data elements and help them to know the data [6].

The consultation with the decision-makers help identify their own needs and that can be relied upon at any later time and be consultation with the service that will help determine their information requirements and to obtain data that can be available and can facilitate dialogues and analysis of individuals in facilitating the identification providers core competencies and to participate the service users that will help determine data requirements and the proposed information raises a lot of privacy and confidentiality consists [7].

Information system provides an overview of the process KPI's in a defined time period (month, quarter, year), including the possibility of obtaining review of the process, organizational units, employee and business partner. The system limit the reviewing of information in accordance with the authorization of a system user, through the personalization of content. The system use data from an existing integrated information system (ERP) and other records necessary to calculate the KPI's of business processes. The system is implemented as a SOA solution, in accordance with the SOA methodology and the use of Silver light technology. A Web portal is created for the interaction between user and system. The user accesses the system, the system performs its identification, records user's activity, and then takes the appropriate data from the business processes records based on them calculates KPI's for the corresponding processes. Finally, the system displays the process performance to the user. All the basic and alternative steps for interactive work are defined.

Detailed instructions for measuring KPI's of supply, which are applied in the private methods individually for each defined KPI's [2],[7]. Silverlight Web portal was developed in Visual Studio 2010 SP1 environment, using C\# programming language for programming "code-behind" classes and Silverlight technologies. Applied is the Form-based user login to the portal is implemented using the Login control. Finally, Silverlight Web portal allows the user different views of graphs and tables with KPI's ratings of supply and sales processes. By calling Prikazi (DISPLAY) the service Performance is called, which calculates and returns the process performance data to Web portal, in accordance with defined parameters, and results are presented in tables and graphs. Both displays are updating by selecting Information or Ratings.

\section{RESULTS}

The current study has shown that establishing a model of key process performance that characterized with standardized criteria to measure the effectiveness of operations and success 
of employees with accompany is possible. The study also has shown that automated collection as well as processing of the needed data related to company could provide accurate, full, and up to date information about how to keep records concerning the process implementation, mainly if these records are governed by appropriate procedures. In addition, the study has shown that short-term performance measurement process could help analyze data on time, and efficiently resolve inconsistencies with the goals of process improvement, products / services and overall company results. Finally, the study has proved that applying solutions presented by this paper could help link IT resources with business goals of the organization, help the organization to build communication with customers and suppliers and internal links of organizational units, allow more accurate, complete information, make crucial quality decisions, and at the same time support key business processes through the increased availability of information which significantly influence increasing the total effectiveness of the company.

\section{DISCUSSION}

To evaluate the performance of companies are using key performance indicators. They help comparing the present performance of the company with the previous one, Standards that measure the industry and even individual industries and accordingly are trying any system of logistic to improve and guide the decisions are made by the standards, which are the rating to later In fact, this idea is considered brilliant and clear about the factors that drive logistics system development and it could be available for a range of adequate targets planning.

\section{CONCLUSION AND FUTURE RECOMMENDATION}

Four reviews of the obtained processes performance are possible: review of KPI's during the specified time period and by months, review of processes ratings during the specified time period and in parallel by months, including the possibility of obtaining these views for individual organizational units, employee and partner, who were involved in implementation of business processes. It is also possible to view KPI's only one process or the review of only one particular KPI's.

\section{ACKNOWLEDGEMENT}

This work was supported by the Deanship of Scientific Research (DSR) at King Abdulaziz University, Jeddah, Saudi Arabia, under Grant No. (830-57-D1436). The author, therefore, gratefully acknowledge the technical and financial support from the DSR.

\section{REFERENCES}

[1] Meier, Horst, et al. "Key performance indicators for assessing the planning and delivery of industrial services." Procedia Cirp 11 (2013): 99-104.

[2] FinPa New Media 2009, Key Performance Indicators, FinPa New Media, Melbourne, viewed $24 \quad$ February 2009, <http://swinburne.projects.finpa.com.au/toolbox10/releases/final/toolbox /resources/res4040/res4040.htm>.

[3] Ballantine J, Brignall S, Modell S. Performance measurement and management in public health services: a comparison of UK and Swedish practice. Management Accounting Research. 1998; 9 pp.71-4.

[4] Kaplan RS, Norton DP. The Balanced Scorecard - Measures that Drive Performance. Harvard Business Review. 1992; 70(1): pp.71-9.

[5] Audit Commission. On Target: the practice of performance indicators. Audit Commission for Local Authorities and the National Health Service in England and Wales; 2000. Available online from: http://www.auditcommission. REPORT/266D51B7-0C33-4b4b-98327484511275E6/archive_mptarget.pdf.

[6] AIHW. A guide to data development. Australian Institute of Health and Welfare (AIHW); Report No.: AIHW Cat. no. HWI 94. 2007.

[7] WHO. Mental Health Information Systems (Mental Health Policy and Service Guidance Package). World Health Organisation; 2005.

[8] Arora, Amishi, and Sukhbir Kaur. "Performance Assessment Model for Management Educators Based on KRA/KPI." International Conference on Technology and Business Management March vol 23.2015. 